Article

\title{
Application of a Land Surface Model Using Remote Sensing Data for High Resolution Simulations of Terrestrial Processes
}

\section{Hyun Il Choi}

Department of Civil Engineering, Yeungnam University, 214-1 Dae-dong, Gyeongsan-si, Gyeongbuk-do 712-749, Korea; E-Mail: hichoi@ynu.ac.kr; Tel.: +82-53-810-2413;

Fax: $+82-53-810-4622$

Received: 10 October 2013; in revised form: 1 December 2013 / Accepted: 3 December 2013 / Published: 9 December 2013

\begin{abstract}
Most current land surface models (LSMs) coupled to regional climate models (RCMs) have been implemented at the several tens of kilometer spatial scales. Modeling land surface processes in LSMs at a finer resolution is necessary for improvements in terrestrial water and energy predictions especially for small catchments. This study has therefore assessed the applicability of high-resolution simulations for terrestrial processes to a small study basin from the Common Land Model (CoLM) using 1-km surface boundary conditions (SBCs) based on remote sensing products. The performance of the CoLM simulations at finer $(1-\mathrm{km})$ and coarser $(30-\mathrm{km})$ resolutions are evaluated for daily runoff and land surface temperature results which have a significant influence on the terrestrial water and energy cycles. The daily stream water temperature is also estimated by a linear regression function of the $1-\mathrm{km}$ daily land surface temperature prediction. The daily stream runoff and temperature results are compared with observations from a stream gauge station, and the daily land surface temperature prediction is compared with the 1-km remote sensing product. It is observed that the high-resolution CoLM results can reasonably capture seasonal variations in both daily runoff and temperatures crucial to the terrestrial water and energy budget.
\end{abstract}

Keywords: land surface model; remote sensing data; surface boundary conditions; runoff; land surface temperature; stream water temperature 


\section{Introduction}

Regional climate models (RCMs) can provide the scientific information for climate variability, changes, and impacts at local and regional scales. The Intergovernmental Panel on Climate Change (IPCC) addressed the vulnerability of water resources to climate change and emphasized the need for high resolution simulations of terrestrial land surface processes in land surface models (LSMs) coupled to RCMs [1]. As current hydrology modeling studies have analyzed the hydrologic system complexity at higher resolutions, LSMs need to incorporate more sophisticated linkages and process interactions at finer scales in supporting of the increasing availability of remote sensing observations and computational power. Land surface parameterizations in LSMs that have been developed with a detailed representation of the hydrologic cycle have been implemented at the resolutions of several tens of kilometers [2-8]. Combined with such improvements in LSMs, finer resolution input datasets utilizing remote sensing products are also necessary for high-resolution LSM simulations to improve model predictability. Improvements in terrestrial water and energy predictions from high-resolution LSM simulations are essential for the watershed forecasting, management and planning.

For assessment on the applicability of high resolution simulations from LSMs for small basins, this study has chosen the Common Land Model (CoLM) [9], a state of the art soil-vegetation-atmosphere transfer (SVAT) model, which has been incorporated into the mesoscale Climate-Weather Research and Forecasting (CWRF) model with numerous crucial updates for land processes [10-12]. The performance of CoLM simulation results has been widely evaluated against field measurements in a standalone mode as driven by the meteorological forcing data [6-9,13-19]. The CoLM can simulate the comprehensive land state variables of soil moisture, soil temperature, snow water equivalent, runoff, and energy fluxes such as net radiation, latent and sensible heat, etc. It has been, however, found that an application of the CoLM requires improvements in predicting the terrestrial hydrologic cycle $[8,19]$. Moreover the coarse resolution simulations in the dynamic responses of land surface processes to the coupled modeling system ultimately may lead to restrictions on model predictability in surface water and energy budget predictions especially for small catchments. The CoLM simulates both water and energy exchanges between land and atmosphere, which are controlled in part by the terrestrial water and heat fluxes. Hence, this study has focused on evaluating the performance of high-resolution simulations for runoff and land surface temperatures from the CoLM at 1-km grid spacing. For a performance assessment of high resolution CoLM simulations, this study selects a small natural basin, the Yongjeon River Basin in the Nakdong River Watershed, Korea where both runoff and temperature observations are available. All terrestrial water and energy schemes in the CoLM are implemented at the grid meshes rather than basins or catchments to avoid downscaling and upscaling exchanges between atmospheric forcings and CoLM predictions. This study has modeled a small basin with the 1-km multiple computational grids under study, which is different from the implementation with a large size single column domain for a small study basin in previous studies [2,4-6]. For comparison of simulation results with different model resolutions, this study has also implemented the CoLM at the $30-\mathrm{km}$ resolution, commonly used in current LSM simulations.

The specification of realistic surface boundary conditions (SBCs) is one of the essential components affecting the representation of surface-atmosphere interactions in LSMs. The primary SBCs for use in the CoLM have been constructed for North America or Asia domain at the 30-km grid scale [20-23]. 
A set of high resolution SBCs based on best observational data is desired for a direct application of the CoLM at the 1-km grid resolution in the study domain. Following Choi [24] this study has constructed two sets of the primary SBCs using remote sensing data for the study basin at 1-km (0.00833 degree) and $30-\mathrm{km}$ ( 0.25 degree) horizontal spacing on the geographic coordinate system. The high quality SBCs based on remote sensing products include the terrain SBCs such as surface topography, bedrock depth, and soil sand/clay fraction profiles, and the vegetative SBCs such as land cover category, surface characteristic identification, fractional vegetation cover, albedo, and leaf area index. For the standalone CoLM simulations, the meteorological forcing data are also constructed onto 1-km and 30-km computational grids by the inverse distance weighting method from daily observations in the Korea Meteorological Administration (KMA) gauge stations around the study basin. The applicability of high-resolution simulations of daily runoff and land surface temperatures in 2009 is initially evaluated at a small spatial and temporal scale for the study basin. Besides, this study has estimated the stream water temperature by the regression analysis between the $1-\mathrm{km}$ simulated land surface temperate and the observed stream water temperature. Since most current LSMs are limited in predicting stream water temperature which is one of the most important factors in water ecosystem and environment managements, an applicable prediction scheme for both stream discharge and water temperature in LSMs is required for the climate change impact assessment on the river water resource system.

This paper is composed five sections as follows: Section 2 presents the key parameterizations for runoff and temperature predictions in the CoLM, Section 3 describes study basin, data, and methods for the CoLM implementations at a finer $(1-\mathrm{km})$ and a coarser $(30-\mathrm{km})$ resolution, Section 4 evaluates the CoLM simulation results at different resolutions against observations over the study basin, and Section 5 addresses the final conclusions with a summary and discussion on limitations and future studies.

\section{Model Description}

\subsection{General Description on CoLM}

As shown in Figure 1, energy and water balance calculations in the CoLM are performed over each computational grid cell for flux exchanges of water and heat between multi-layer soil grids and overlying atmospheric grids at every time step. Major characteristics of the CoLM include: a 10-layer soil temperature and moisture prediction; a 5-layer snow processes; a mass treatment of liquid and ice water in soil and snow with changes in phase; and a canopy photosynthesis-conductance scheme including the simultaneous transfer of carbon dioxide and water vapor in vegetation. Choi and Liang [8] addressed several deficiencies in the existing formulations for terrestrial hydrologic processes in the CoLM and presented improved solutions focusing on runoff prediction. In particular, they incorporated a spatial distribution of the realistic bedrock depth for more actual estimates of the soil water capacity. The existing equilibrium approximation for the water table depth was replaced with a dynamic prediction scheme for more reasonable predictions of the water table depth. An exponential decay profile of the saturated hydraulic conductivity with soil depth was incorporated for soil macropore effects near the ground surface soil. A set of the abnormal soil water prevention scheme such as an effective hydraulic conductivity of liquid water in the frozen soil and a maximum surface infiltration limit was employed for numerically stable soil moisture solutions. The baseflow (saturation lateral 
runoff component controlled by topography) was added for an additional contribution to subsurface runoff. They demonstrated that such improvement has a significant influence on runoff predictions especially at peak discharges under high flow conditions.

Figure 1. Conceptual schematic for hydrological and biogeophysical processes simulated in the Common Land Model (CoLM).

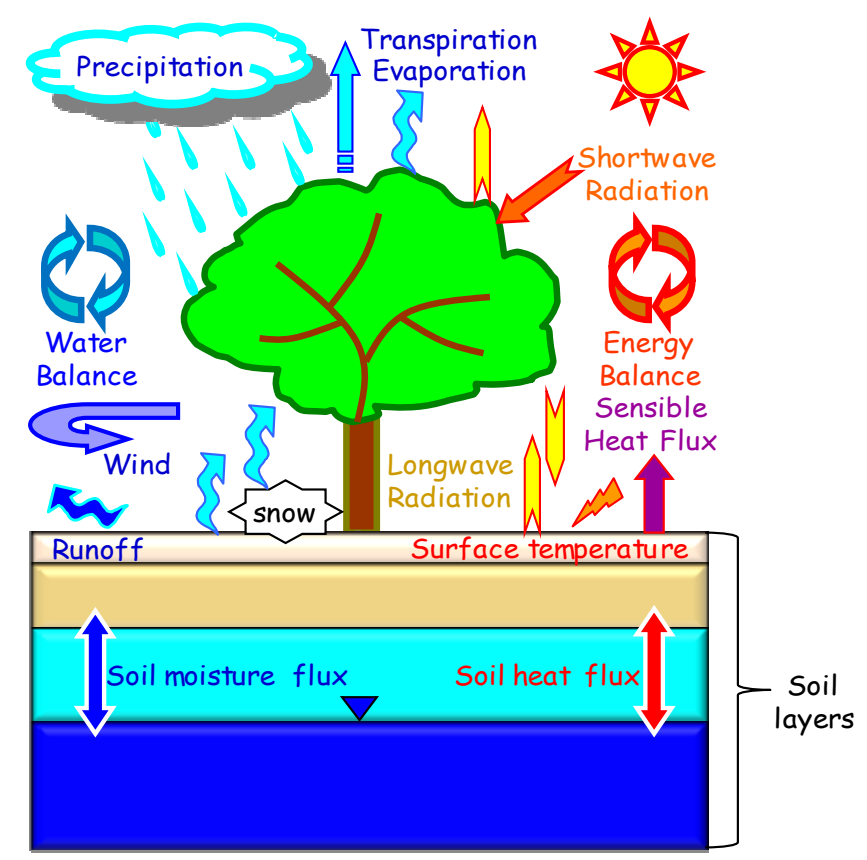

\subsection{Runoff Simulation Scheme}

In recent version of the CoLM, the saturated hydraulic conductivity decreases exponentially with soil depth as developed by Beven and Kirkby [25], Beven [26,27], and Elsenbeer et al. [28]:

$$
K_{s z}=K_{s} e^{-f\left(z-z_{c}\right)}
$$

where $K_{s z}$ is the vertical saturated hydraulic conductivity, $K_{s}$ is the compacted hydraulic conductivity at saturation, $f$ is the decay factor obtained by calibrating the recession curve in the observed hydrograph, and $z_{c}$ is the compacted depth representing soil macropore effect near the soil surface [29], especially in vegetated areas. The vertical saturated conductivity is assumed to have reached the compacted value at the plant root depth $[2,3]$. The soil hydraulic conductivity $K$ is finally expressed as a function of soil wetness $w$ (ratio of the actual soil moisture to porosity) and the pore size distribution index $b$ by Brooks and Corey [30]:

$$
K=K_{s z} w^{2 b+3}
$$

Total runoff is comprised of surface runoff $R_{s}$ and subsurface runoff $R_{s b}$ for each grid cell in the CoLM. Surface runoff $R_{s}$ is generated by the Horton and the Dunn mechanisms as:

$$
R_{s}=\underbrace{\left(1-F_{\text {imp }}\right) \max \left[0, Q_{w}-I_{\max }\right]}_{\text {Hortonian }}+\underbrace{F_{\text {imp }} Q_{w}}_{\text {Dunnian }}
$$


where $Q_{w}$ is the available water supply rate on the surface, $I_{\max }$ is the maximum potential infiltration rate, and $F_{\text {imp }}$ is the impermeable area fraction consisting of the fractional saturated area $F_{\text {sat }}$ and the frozen area $F_{f r z}$ as follows:

$$
F_{i m p}=\left(1-F_{f r z}\right) F_{s a t}+F_{f r z}
$$

The frozen area $F_{f r z}$ is defined as a function of liquid soil water content $\theta_{\text {liq }}$ and ice content $\theta_{i c e}$ at soil layer $k$ :

$$
F_{f r z}(k)=\frac{\theta_{i c e}(k)}{\theta_{\text {liq }}(k)+\theta_{\text {ice }}(k)}
$$

Moreover, Niu and Yang [5] simplified the fractional saturated area $F_{\text {sat }}$ determined by the topographic characteristics and soil moisture state as:

$$
F_{\text {sat }}=F_{\max } e^{-0.5 f \cdot z_{\nabla}}
$$

where $F_{\max }$ is the maximum saturated fraction, and $z_{\mathrm{Q}}$ is the water table depth. The exponent coefficient 0.5 is derived by the comparison of results with the three-parameter gamma distribution of Niu et al. [6].

While the original CoLM implements bottom drainage and saturation excess runoff for the subsurface runoff prediction, the baseflow (saturated lateral runoff controlled by topography) is additionally incorporated in the subsurface runoff scheme in the current CoLM $[2-6,8,13]$. In the CoLM parameterization, therefore, subsurface runoff $R_{s b}$ consists of the three components as:

$$
R_{s b}=\underbrace{R_{\text {bas, max }} e^{-f z_{\nabla}}}_{\text {baseflow }}+\underbrace{\left(1-F_{\text {imp }}\right) K\left(z_{N}\right)}_{\text {bottom drainage }}+\underbrace{\max \left[0,\left(\sum_{k=1}^{N} \theta(k) \Delta z_{k}-\sum_{k=1}^{N} \theta_{s}(k) \Delta z_{k}\right) / \Delta t\right]}_{\text {saturation excess }}
$$

where $R_{\text {bas,max }}$ is the maximum baseflow coefficient determined by calibrations, $\theta$ and $\theta_{s}$ are the volumetric water content and porosity, respectively, $\Delta z_{k}$ is a layer thickness between vertical coordinates $z_{k}$ and $z_{k-1}$ for the layer $k, z_{N}$ is the bottom of the lowest soil layer, $N$ is the total number of model soil layers, and $\Delta t$ is a computational time-increment.

\subsection{Soil Temperature Simulation Scheme}

The heat flux $\Phi_{g}$ into the snow or soil surface from the overlying atmosphere is:

$$
\Phi_{g}=S_{g}-L_{g}-H_{g}-L_{v} E_{g}
$$

where $S_{g}$ is the solar radiation absorbed by the ground $\left[\mathrm{W} \cdot \mathrm{m}^{2}\right], L_{g}$ is the net longwave radiation absorbed by the ground $\left[\mathrm{W} \cdot \mathrm{m}^{2}\right], H_{g}$ is the sensible heat flux from the ground $\left[\mathrm{W} \cdot \mathrm{m}^{2}\right], L_{v}$ is the latent heat of evaporation for water $\left[\mathrm{J} \cdot \mathrm{kg}^{-1}\right]$, and $E_{g}$ is the evaporation from ground $\left[\mathrm{kg} \cdot \mathrm{m}^{-2} \cdot \mathrm{s}^{-1}\right] . L_{v} E_{g}$ is the latent heat flux from the ground $\left[\mathrm{W} \cdot \mathrm{m}^{-1}\right]$. The heat transfer in soil and snow layers is assumed to follow the heat diffusion equation:

$$
c \frac{\partial T}{\partial t}=-\frac{\partial \Phi}{\partial z}+\sigma
$$


where $T$ is the soil or snow heat temperature $[\mathrm{K}], c$ is the volumetric soil or snow heat capacity $\left[\mathrm{J} \cdot \mathrm{m}^{-3} \cdot \mathrm{K}^{-1}\right]$, and $\sigma$ is the latent heat of phase change $\left[\mathrm{W} \cdot \mathrm{m}^{-3}\right]$. The subsurface heat flux $\Phi$ at depth $z$ (positive downward) can be described by the Fourier law for heat conduction:

$$
\Phi=-\lambda \frac{\partial T}{\partial z}
$$

where $\lambda$ is the thermal conductivity $\left[\mathrm{W} \cdot \mathrm{m}^{-1} \cdot \mathrm{K}^{-1}\right]$. By combining Equations (9) and (10), the soil and snow layer temperatures are computed based on the second law of heat conduction in one-dimensional form:

$$
c \frac{\partial T}{\partial t}=\frac{\partial}{\partial z}\left[\lambda \frac{\partial T}{\partial z}\right]+\sigma
$$

This equation is solved numerically to calculate soil temperatures for a 10-layer soil column with up to five overlaying layers of snow with the boundary conditions of the heat flux into the surface snow or soil layer from the overlying atmosphere as shown in Equation (8) and zero heat flux at the bottom of the soil column.

\section{Model Setup}

\subsection{Study Basin}

To appropriately evaluate the performance of high-resolution simulations from the CoLM, this study has selected a small natural basin under study, the Yongjeon River Basin in the Nakdong River Watershed, Korea. This selected study basin has natural flow conditions without river regulation effects on flow discharge and temperature, which are not explicitly simulated in current LSMs.

Figure 2a shows the location of the Korean Peninsula, and Figure $2 \mathrm{~b}$ denotes the location of the study basin overlaid with the main stream networks and the watershed boundary of the Nakdong River on the geographic coordinate system. The study basin comprises of 412 computational grid cells at $1-\mathrm{km}$ (0.00833 degree) horizontal spacing and a single grid at 30-km ( 0.25 degree) scale, respectively, which is a subset of the computational domain for the Nakdong River Watershed in Choi [24]. This study basin has a stream gauge station Yongjeon-A (For convenience, this gauge station name is referred as to Y-A hereafter.) near the drainage outlet which observes both stream flow discharges and water temperatures for 42 times in 2009 by the KMA. There are six meteorological gauge stations managed by the KMA around the study basin for daily observations. See the Section 3.3 for details on the gauge stations and observations.

\subsection{Surface Boundary Conditions}

For high-resolution CoLM simulations, this study has constructed the most comprehensive SBCs based on the best observational data over the Nakdong River Watershed. The primary set of SBCs required for the CoLM applications includes the terrain SBCs such as surface topography, bedrock depth, and soil sand/clay fraction profiles, and the vegetative SBCs such as land cover category, surface characteristic identification, fractional vegetation cover, albedo, and leaf area index. The remote sensing based observational data at the finest possible resolution were collected for constructing a comprehensive set of SBCs in the study domain. 
Figure 2. (a) Location map of the Korean Peninsula overlaid with latitude and longitude lines and (b) locations of gauge stations and the study basin overlaid with the main stream networks and the watershed boundary of the Nakdong River.

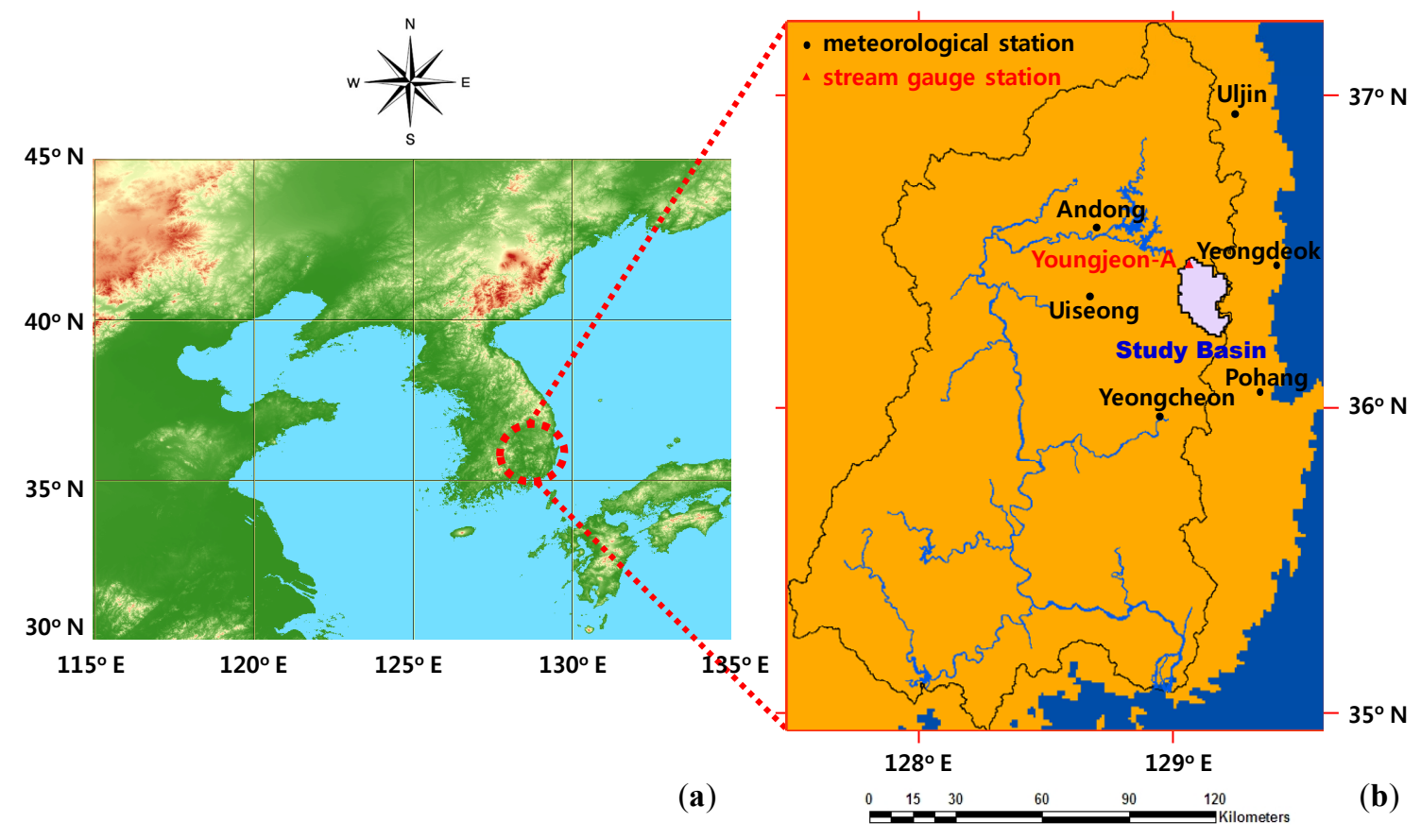

Topographic characteristics were constructed from a finer resolution terrain data derived from remote sensing techniques, the National Aeronautics and Space Administration (NASA) Shuttle Radar Topographic Mission (SRTM) digital elevation model (DEM) based on the global 3-arc-second (approximately $90 \mathrm{~m}$ resolution) dataset [31]. The CoLM requires the spatially distributed bedrock depth to estimate the actual soil water capacity, and soil sand and clay fraction profiles are required to parameterize soil thermal and hydraulic properties. These profiles were determined by a new comprehensive Harmonized World Soil Database (HWSD) [32] developed by the Land Use Change (LUC) project of International Institute for Applied Systems Analysis (IIASA) and the Food and Agriculture Organization of the United Nations (FAO). The HWSD soil data are available at a 30 -arc-second (approximately $1 \mathrm{~km}$ resolution) raster database with over 16,000 different soil mapping units, which combines existing regional and national updates of soil information worldwide.

This study has constructed the vegetative SBCs following Choi [24]. The land cover information and surface characteristic identification in the model were adopted from the US Geological Survey (USGS) 24-category land cover classification system [33], developed using the global 1-km resolution advanced very high resolution radiometer (AVHRR) satellite-derived normalized difference vegetation index (NDVI) composites [34]. Following Zeng et al. [35,36], the fractional vegetation cover was derived from the 1-km NDVI data in the Système Pour l'Observation de la Terre-VEGETATION (SPOT-VGT) satellite products [37]. The surface albedo was adopted from the 1-km Moderate Resolution Imaging Spectroradiometer (MODIS) data [38], reclassified with the 1-km USGS 24-category land cover categories by Yucal [39]. The monthly mean distributions of leaf area index (LAI) were constructed from the MODIS data at 1-km spacing. See Choi [24] for the details of data characteristics and construction methods for the vegetative SBCs. 
Figure 3 depicts the spatial distributions of several SBCs at 1-km computational grids over the study basin for terrain elevation ranging from 180 to $802 \mathrm{~m}$, and land cover types consisting of irrigated cropland and pasture, cropland/woodland mosaic, savanna, and mixed forest. The albedo values vary from 0.13 to 0.20 . Besides, red boxes in Figure 3 represent a 30-km computational grid for the study basin for which the mean terrain elevation is $399 \mathrm{~m}$, the major land cover type is savanna, and the representative albedo value is 0.20 . The CoLM identifies the surface characteristics as eight categories, namely: urban and built-up, soil, wetland, glacier, shallow lake, deep lake, sea ice, and ocean. The surface characteristic identification is determined as the soil only, and the fractional vegetation cover is computed as 1.0 for all the computational grid meshes in this natural study basin. The HWSD soil data provides a single value uniformly over the study basin such as $80 \mathrm{~cm}$ of the bedrock depth, and 0.59 and $0.56(0.25$ and 0.27$)$ of the sand (clay) fractions for the upper five layers and the rest soil layers, respectively in the CoLM soil layers. Figure 4 illustrates seasonal LAI variations of spatial distributions of $1-\mathrm{km}$ grids along with the $30-\mathrm{km}$ grid value for MAM (March-April-May), JJA (June-July-August), SON (September-October-November), and DJF (December-January-February) average over the study basin.

Figure 3. Spatial distributions of 1-km grids and representative values of a 30-km grid (red box and value) for (a) surface topography, (b) albedo, and (c) land cover category over the study basin.

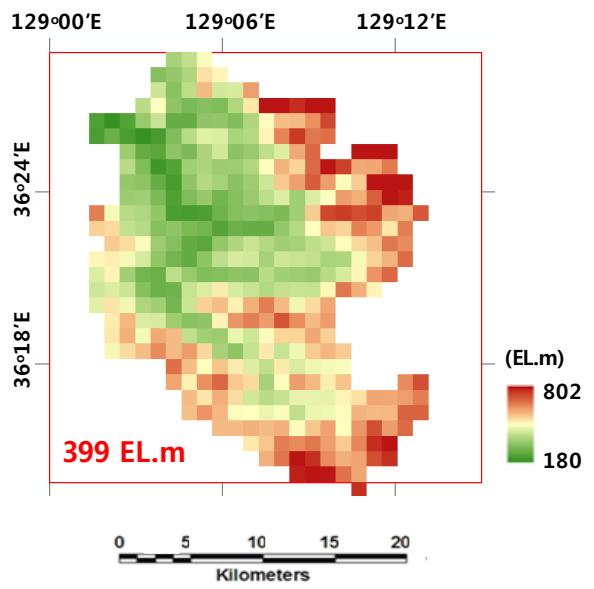

(a)

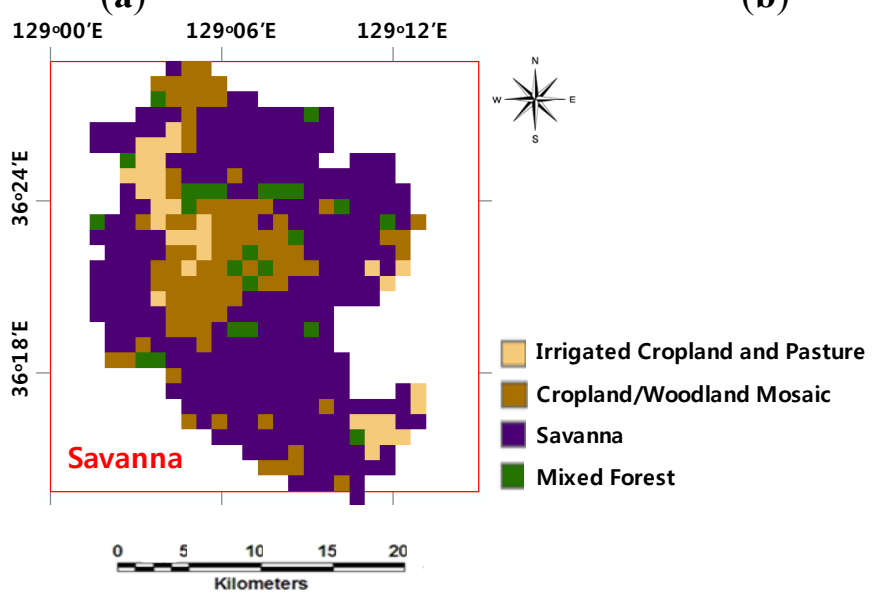

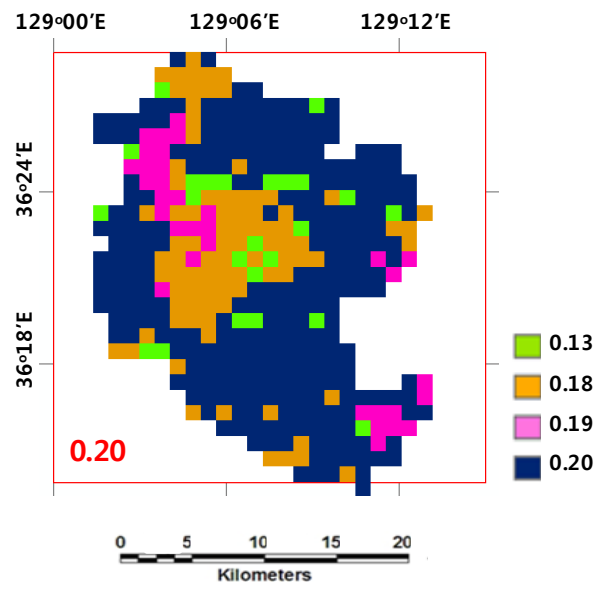

(b)

(c) 
Figure 4. Spatial distributions of 1-km grids and representative values of a 30-km grid (red box and value) for the seasonal average leaf area index (LAI) in (a) March-April-May (MAM), (b) June-July-August (JJA), (c) September-October-November (SON), and (d) December-January-February (DJF) over the study basin.
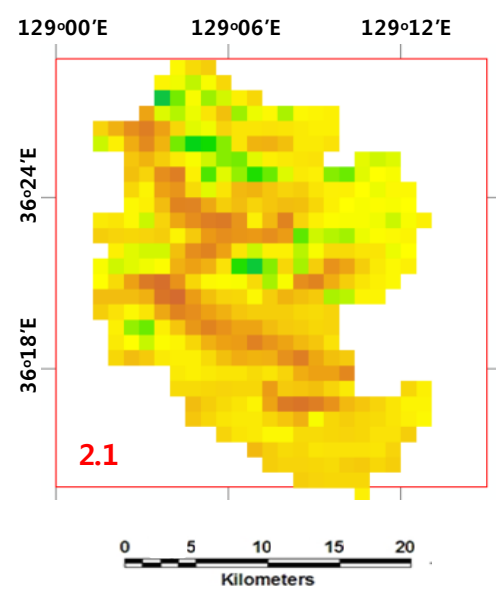

(a)

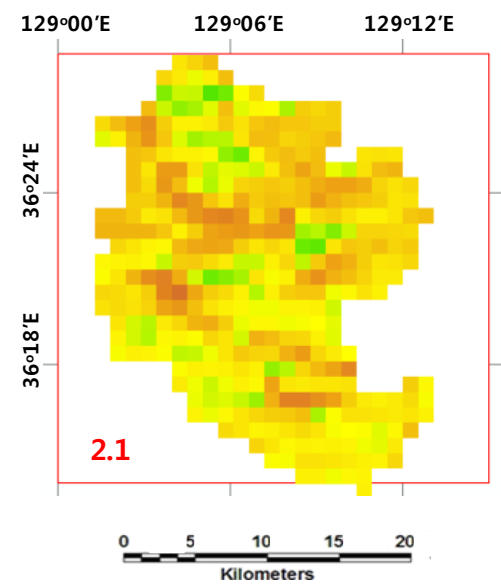

(c)

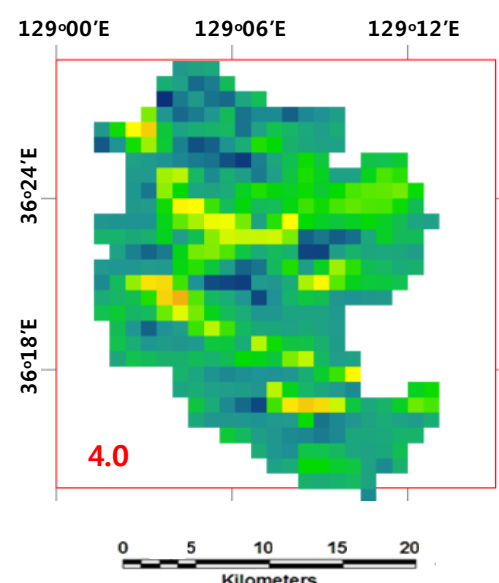

(b)

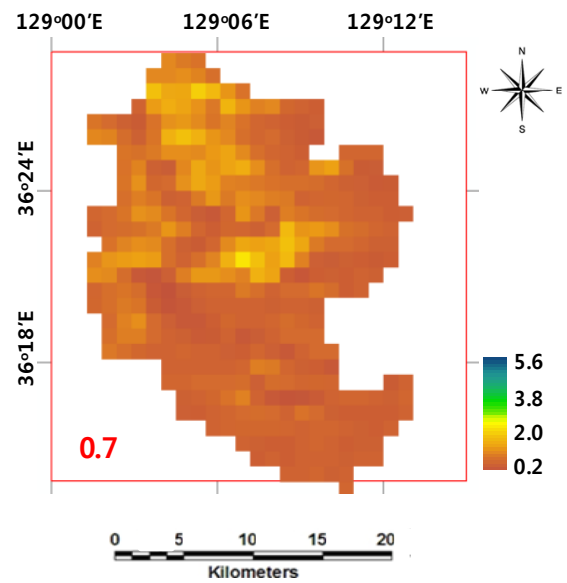

(d)

\subsection{Meteorological Forcing and Initial Conditions}

The standalone CoLM simulations are driven by the meteorological forcing data constructed from daily observations in six gauge stations by the KMA such as Andong, Uiseong, Yeongcheon, Pohang, Yeongdeok, and Uljin stations shown in Figure $2 \mathrm{~b}$. Table 1 shows the atmospheric variables required for the CoLM simulations in the offline mode. The daily meteorological data measured from six KMA gauge stations are required for both spatial and temporal interpolations for the CoLM runs. Most forcing data are constructed onto the computational grids from six meteorological stations around the study basin by the inverse distance weighting method, which is a type of multivariate interpolation with a scattered set of point values. The computational grid point values at $1-\mathrm{km}$ and $30-\mathrm{km}$ resolutions are calculated with a weighted average of the values available at six gauge station points by the weighting of the inverse of the distance to each gauge point. The daily forcing data are also linearly interpolated for the computational time step of 3,600 seconds. A spin-up strategy is adopted for 
uncertainty in initial conditions. The model is started at 00:00 on 1 January 2009 by the assumed initial values and run repeatedly for five cycles throughout the whole year of 2009. The results at the end of the fifth cycle are used as the initial conditions for the subsequent CoLM simulation.

Table 1. Meteorological forcing data required to drive the CoLM in the offline mode.

\begin{tabular}{ll}
\hline Variable & Unit \\
\hline pressure at the lowest atmospheric layer & $\mathrm{Pa}$ \\
temperature at the lowest atmospheric layer & $\mathrm{K}$ \\
specific humidity at the lowest atmospheric layer & $\mathrm{kg} / \mathrm{kg}$ \\
zonal wind at the lowest atmospheric layer & $\mathrm{m} / \mathrm{s}$ \\
meridional wind at the lowest atmospheric layer & $\mathrm{m} / \mathrm{s}$ \\
the lowest atmospheric layer height & $\mathrm{m}$ \\
pressure at surface & $\mathrm{Pa}$ \\
convective rainfall & $\mathrm{mm}$ \\
resolved rainfall & $\mathrm{mm}$ \\
snow & $\mathrm{mm}$ \\
planetary boundary layer height & $\mathrm{m}$ \\
downward long wave radiation onto the surface & $\mathrm{W} / \mathrm{m}^{2}$ \\
downward short wave flux at ground surface & $\mathrm{W} / \mathrm{m}^{2}$ \\
\hline
\end{tabular}

\section{Results and Discussion}

For the performance evaluation of the CoLM simulations at finer and coarser resolutions, the runoff and temperature simulation results were compared with observations of comparatively sparse data. A stream gauge station Y-A around the outlet has both stream discharge and temperature observations measured for 42 times in 2009 by the KMA, and the 8-day MODIS land surface temperature data are available at $1-\mathrm{km}$ grid spacing for the study basin. Hence daily runoff directly simulated from the CoLM at $1-\mathrm{km}$ and $30-\mathrm{km}$ resolutions and daily water temperature estimated from the $1-\mathrm{km}$ land surface temperature result were compared with 42 observations available at irregular intervals. The $1-\mathrm{km}$ and $30-\mathrm{km}$ simulation results of daily land surface temperatures were compared with 46 observations available at every 8 days over the study basin in 2009. The relative agreement between results and observations were evaluated by using the Nash-Sutcliffe coefficient (NSC) [40] and the mean absolute error $(M A E)$ :

$$
\begin{gathered}
N S C=1-\frac{\sum_{i=1}^{n}\left(O_{i}-S_{i}\right)^{2}}{\sum_{i=1}^{n}\left(O_{i}-O_{a}\right)^{2}} \\
M A E=\frac{1}{n} \sum_{i=1}^{n}\left|O_{i}-S_{i}\right|
\end{gathered}
$$

where $n$ is the total number of data for comparison, $O_{i}$ and $S_{i}$ are the observed and simulated values at day $i$ respectively, and $O_{a}$ is the average value of $O_{i}$. NSC can measure the model ability to simulate observation amplitudes, and $M A E$ is used to evaluate how close predictincsons are to observations. 


\subsection{Runoff Results}

Both CoLM simulation results at finer $(1-\mathrm{km})$ and coarser $(30-\mathrm{km})$ resolutions are first evaluated for runoff results against stream flow observations at the KMA stream gauge station Y-A around the outlet in the study basin. Total runoff results consisting of surface and subsurface runoff from the CoLM simulations are averaged for $1-\mathrm{km}$ grids and selected for a 30-km grid point, respectively, corresponding to the study basin to be compared with stream flow observations at the gauge station $\mathrm{Y}-\mathrm{A}$ in the study basin.

Table 2. Comparison of the CoLM performance at $1-\mathrm{km}$ and $30-\mathrm{km}$ resolutions for total runoff by the Nash-Sutcliffe coefficient NSC and the mean absolute error MAE with the decay factor $f\left(\mathrm{in} \cdot \mathrm{m}^{-1}\right.$ ) and the maximum baseflow coefficient $R_{b a s, \max }(\mathrm{in} \mathrm{mm} / \mathrm{sec}$ ) changes for the study basin in 2009 .

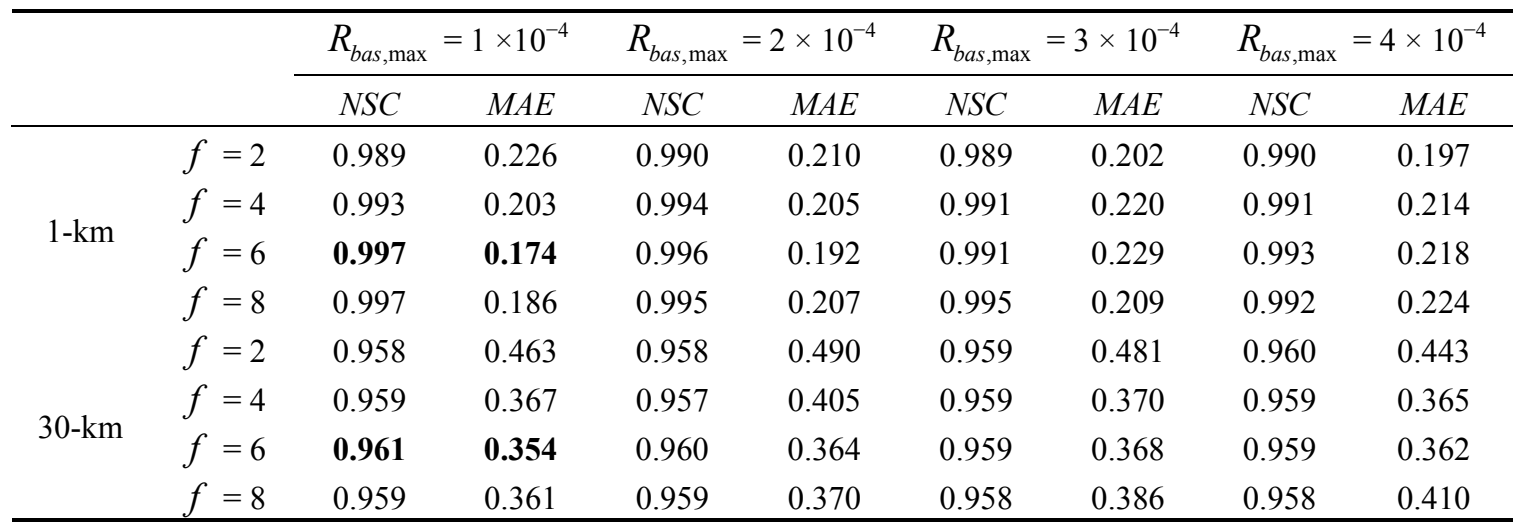

For the model calibration in runoff simulations of the year 2009 from the CoLM at both $1-\mathrm{km}$ and $30-\mathrm{km}$ resolutions, this study has examined the sensitivity of the two parameters, the decay factor $f$ ( 2 to $8 \mathrm{~m}^{-1}$ ) and the maximum baseflow coefficient $R_{\text {bas, } \max }\left(1 \times 10^{-4}\right.$ to $4 \times 10^{-4} \mathrm{~mm} / \mathrm{s}$ ), as suggested by Choi et al. [41]. It was found that changes of both calibration parameters $f$ and $R_{\text {bas,max }}$ do not strongly affect the runoff results, mainly due to lower baseflow generation in the CoLM, similarly to the results obtained by Choi and Liang [8]. It is also caused by a relatively shallower HWSD bedrock depth data $(80 \mathrm{~cm})$ and the exponentially decayed hydraulic conductivity that may limit soil water availability and confine soil water at upper soil layers. As illustrated in Table 2, the decay factor $f$ of $6 \mathrm{~m}^{-1}$ and the maximum baseflow coefficient $R_{b a s, \max }$ of $1 \times 10^{-4} \mathrm{~mm} / \mathrm{s}$ are selected for the model calibration parameters at both $1-\mathrm{km}$ and $30-\mathrm{km}$ resolution simulations for the study basin. For all simulated runoff results, a finer (1-km) resolution CoLM shows an improved performance (higher NSC and lower MAE scores) compared to the results from a coarser $(30-\mathrm{km})$ resolution CoLM. Simulated runoff using the two calibrated parameters yields an NSC of 0.997 and 0.961 for the $1-\mathrm{km}$ and $30-\mathrm{km}$ resolutions, respectively, and an $M A E$ of 0.174 and 0.354 for $1-\mathrm{km}$ and $30-\mathrm{km}$ results, respectively. Especially, $M A E$ is reduced by around $49 \%$ for the $1-\mathrm{km}$ runoff results compared to the $30-\mathrm{km}$ simulations.

Figure 5 compares the time series of specific discharges (per unit drainage area) during 2009, daily simulated from the CoLM at $1-\mathrm{km}$ and $30-\mathrm{km}$ resolutions under the calibrated parameter values $\left(f=6 \mathrm{~m}^{-1}\right.$ and $R_{\text {bas, } \max }=1 \times 10^{-4} \mathrm{~mm} / \mathrm{s}$ ) and observed for 42 times at the KMA gauge station Y-A in the study basin. The hyetographs of the observed total precipitation over the study basin are plotted along the 
secondary vertical axis. In general, both $1-\mathrm{km}$ and 30-km CoLM runoff simulation results show quick responses to rainfall events with less recession time, which are similar regardless of different values of the two calibration parameters $f$ and $R_{\text {bas,max }}$ in this study basin. Especially, under high flow conditions, the $30-\mathrm{km}$ CoLM for a grid point simulates runoff with higher and sharper peaks than the basin-wide mean result from the 1-km CoLM. As illustrated in Table 2 and Figure 5, the performance of a finer $(1-\mathrm{km})$ resolution CoLM runoff is better than a coarser $(30-\mathrm{km})$ resolution result. Seasonal variations of the high resolution CoLM runoff can generally capture the seasonal variability of stream flow discharges, although runoff results cannot be fully evaluated by the limited 42 observations available in 2009.

Figure 5. Comparison of daily time series of total runoff simulated from the CoLM at $1-\mathrm{km}$ and $30-\mathrm{km}$ resolutions along with 42 stream flow observations at the Korea Meteorological Administration (KMA) stream gauge station Y-A and the daily observed total precipitation for the study basin in 2009.

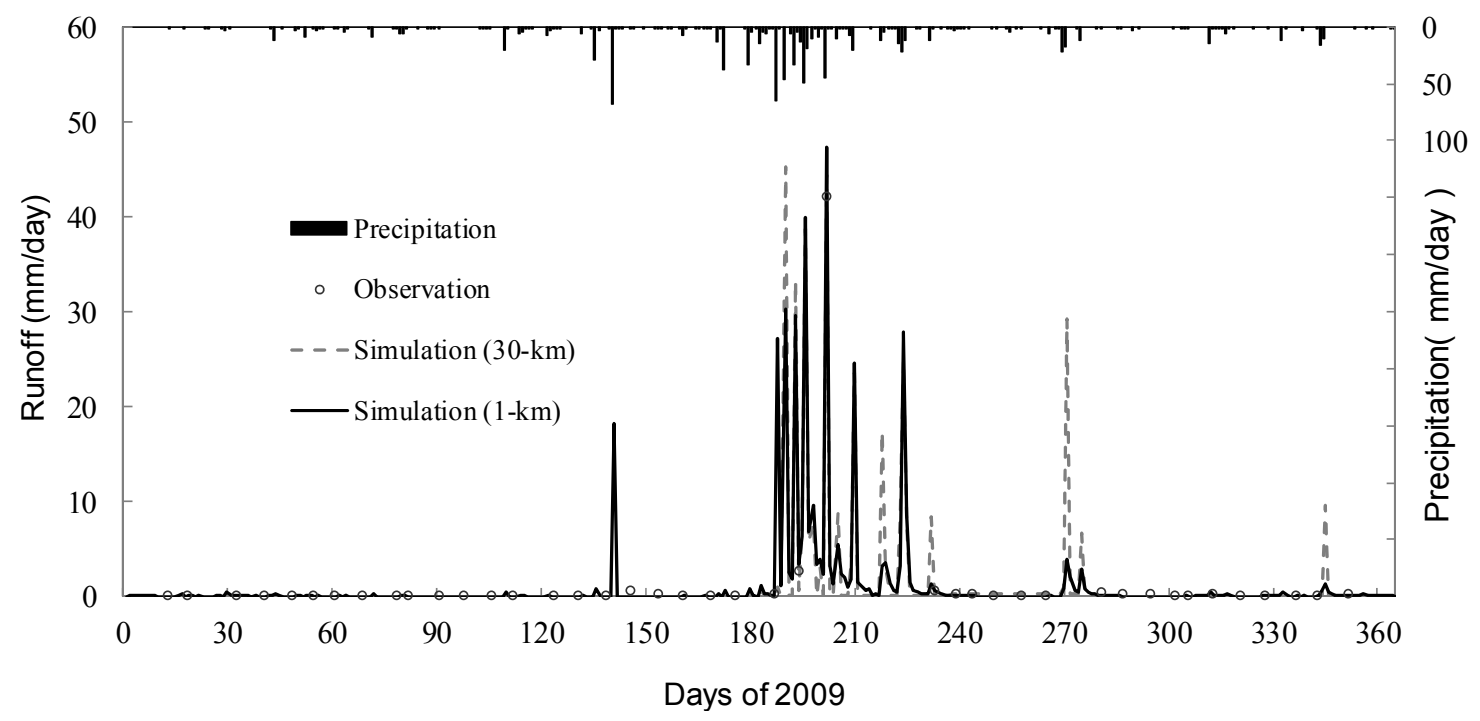

\subsection{Land Surface Temperature Results}

This study has also performed the comparison of land surface temperatures daily simulated from the CoLM at $1-\mathrm{km}$ and $30-\mathrm{km}$ resolutions and observed at 8 -day interval from the MODIS for the study basin. Note that the performance of land surface temperature results was compared with respect to the two hydrologic parameters since no parameter was calibrated for the land surface temperature simulations. As shown in Table 3, with the same values of the two parameters $\left(f=6 \mathrm{~m}^{-1}\right.$ and $R_{\text {bas, } \max }=1 \times 10^{-4} \mathrm{~mm} / \mathrm{s}$ ) in runoff results, the $1-\mathrm{km}$ land surface temperature results have a good agreement with observations with $N S C=0.868$ and $M A E=2.258$, while all of the daily NSC and MAE values from the $30-\mathrm{km}$ CoLM results are below 0.7 and above 3.8, respectively. Especially, the performance of the $1-\mathrm{km}$ land surface temperature results show around $58 \%$ reduction in $M A E$ compared to the $30-\mathrm{km}$ simulation results. 
Table 3. Comparison of the CoLM performance at $1-\mathrm{km}$ and $30-\mathrm{km}$ resolutions for land surface temperatures by the Nash-Sutcliffe coefficient NSC and the mean absolute error $M A E$ with the decay factor $f\left(\mathrm{in} \cdot \mathrm{m}^{-1}\right)$ and the maximum baseflow coefficient $R_{\text {bas, } \max }$ (in $\mathrm{mm} / \mathrm{s}$ ) changes for the study basin in 2009 .

\begin{tabular}{|c|c|c|c|c|c|c|c|c|c|}
\hline & & \multicolumn{2}{|c|}{$R_{\text {bas,max }}=1 \times 10^{-4}$} & \multicolumn{2}{|c|}{$R_{b a s, \max }=2 \times 10^{-4}$} & \multicolumn{2}{|c|}{$R_{b a s, \max }=3 \times 10^{-4}$} & \multicolumn{2}{|c|}{$R_{b a s, \text { max }}=4 \times 10^{-4}$} \\
\hline & & NSC & $M A E$ & $N S C$ & $M A E$ & $N S C$ & $M A E$ & NSC & $M A E$ \\
\hline \multirow{4}{*}{$1-\mathrm{km}$} & $f=2$ & 0.832 & 2.632 & 0.830 & 2.648 & 0.829 & 2.651 & 0.830 & 2.645 \\
\hline & $f=4$ & 0.860 & 2.366 & 0.859 & 2.376 & 0.859 & 2.378 & 0.859 & 2.376 \\
\hline & $f=6$ & 0.868 & 2.258 & 0.868 & 2.261 & 0.868 & 2.263 & 0.868 & 2.261 \\
\hline & $f=8$ & 0.866 & 2.270 & 0.866 & 2.269 & 0.866 & 2.269 & 0.866 & 2.269 \\
\hline \multirow{4}{*}{$30-\mathrm{km}$} & $f=2$ & 0.669 & 3.957 & 0.667 & 3.975 & 0.668 & 3.965 & 0.671 & 3.923 \\
\hline & $f=4$ & 0.673 & 3.888 & 0.673 & 3.891 & 0.672 & 3.906 & 0.672 & 3.898 \\
\hline & $f=6$ & 0.675 & 3.883 & 0.675 & 3.883 & 0.675 & 3.883 & 0.675 & 3.883 \\
\hline & $f=8$ & 0.673 & 3.898 & 0.673 & 3.898 & 0.673 & 0.898 & 0.672 & 3.899 \\
\hline
\end{tabular}

Figure 6 compares the time series of the land surface temperature during 2009, daily simulated from the CoLM at 1-km and 30-km resolutions and 8-day observed from the MODIS over the study basin. Both $1-\mathrm{km}$ and $30-\mathrm{km}$ CoLM simulation results generally capture the seasonal trend and variability of the observed land surface temperature for the study basin, but a coarser $(30-\mathrm{km})$ resolution result shows more seasonal fluctuations and biases to the observation than a finer $(1-\mathrm{km})$ resolution result. It is mainly caused by a single value representation at the $30-\mathrm{km}$ scale for the study basin. Although this initial $1-\mathrm{km}$ resolution result from the CoLM overestimates land surface temperatures in summer and produces underestimation in winter, it is expected that the high resolution CoLM simulation can improve the land surface temperature predictability, crucial to the terrestrial water and energy budget.

Figure 6. Comparison of daily time series of land surface temperatures simulated from the CoLM at 1-km and 30-km resolutions along with 8-day MODIS observations from the $1-\mathrm{km}$ MODIS for the study basin in 2009.

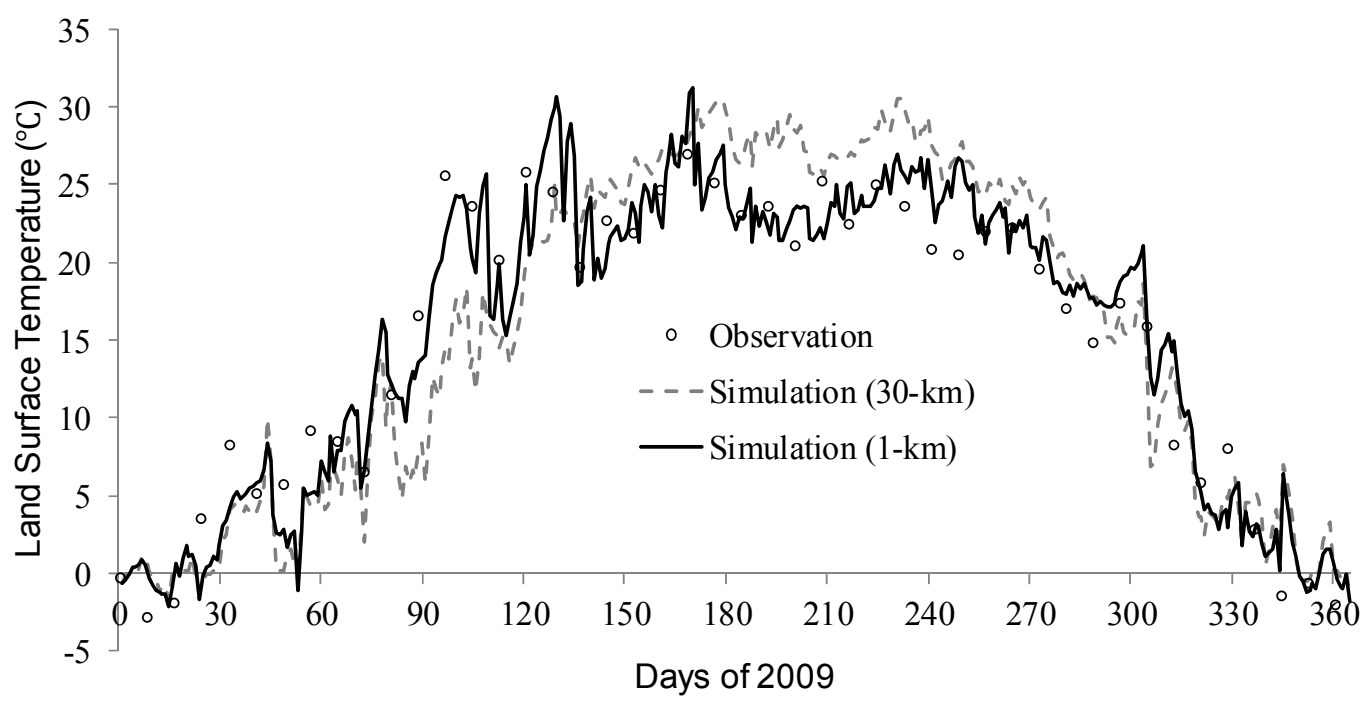


Figure 7 also illustrates the seasonal variations of land surface temperatures simulated from the CoLM at $1-\mathrm{km}$ and $30-\mathrm{km}$ resolutions for MAM, JJA, SON, and DJF average values over the study basin. While a coarser resolution CoLM results are determined by a single $30-\mathrm{km}$ gird value only, a finer resolution CoLM can simulate the spatial variability of land surface temperatures for 1-km grids over the study basin.

Figure 7. Spatial distributions of 1-km grids and representative values of a $30-\mathrm{km}$ grid (red box and value) for the seasonal average of land surface temperatures simulated from the CoLM in (a) MAM, (b) JJA, (c) SON, and (d) DJF over the study basin.

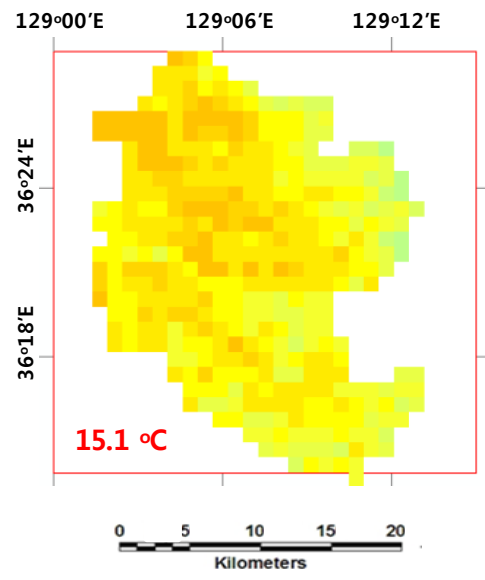

(a)

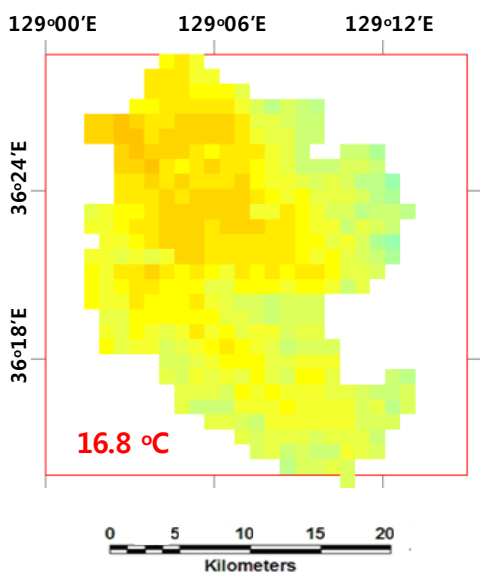

(c)

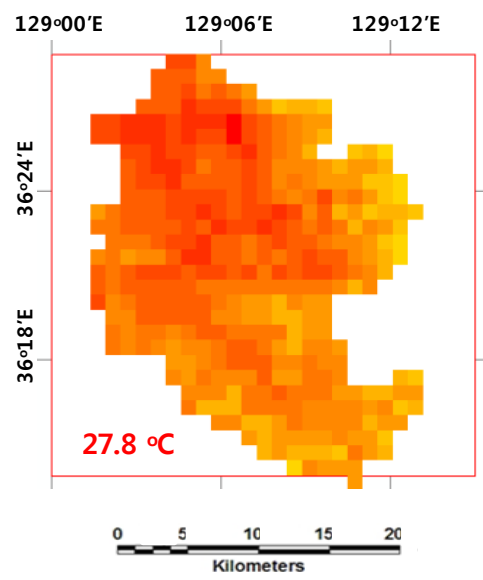

(b)

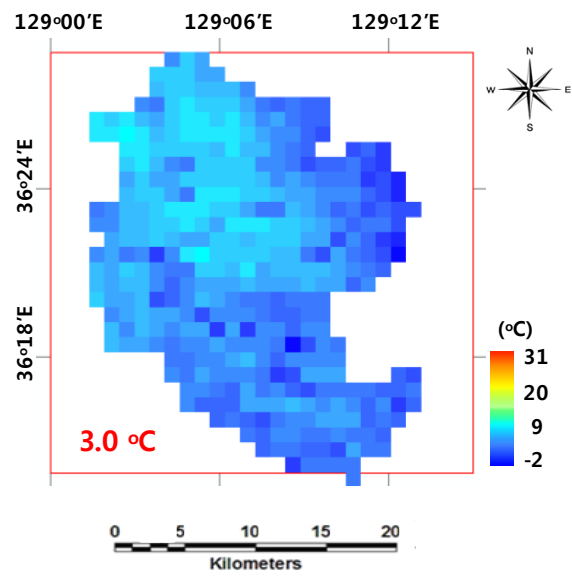

(d)

\subsection{Stream Water Temperature Estimations}

Like most LSMs, the current CoLM cannot predict directly the stream water temperature which may significantly affect the water quality and the habitat suitability of aquatic species. Hence this study has proposed a method to estimate the stream water temperature by the regression analysis of the relation between the simulated land surface temperature and the observed stream water temperature data.

Figure 8 illustrates the scatter plot of the observed stream water temperature versus the simulated land surface temperature from the $1-\mathrm{km}$ CoLM. The observed stream water temperature $T_{s t r}$ for the study basin shows a linear relation to the simulated land surface temperature $T_{s f c}$ with the high 
coefficient of determination $R^{2}=0.929$. The regression equation for estimating stream water temperatures in this study basin from the CoLM land surface temperatures is:

$$
T_{s t r}=0.8367 T_{s f c}+2.718
$$

Figure 8. Comparison of trends between 1-km simulated land surface temperatures and observed stream water temperatures for the study basin in 2009 .

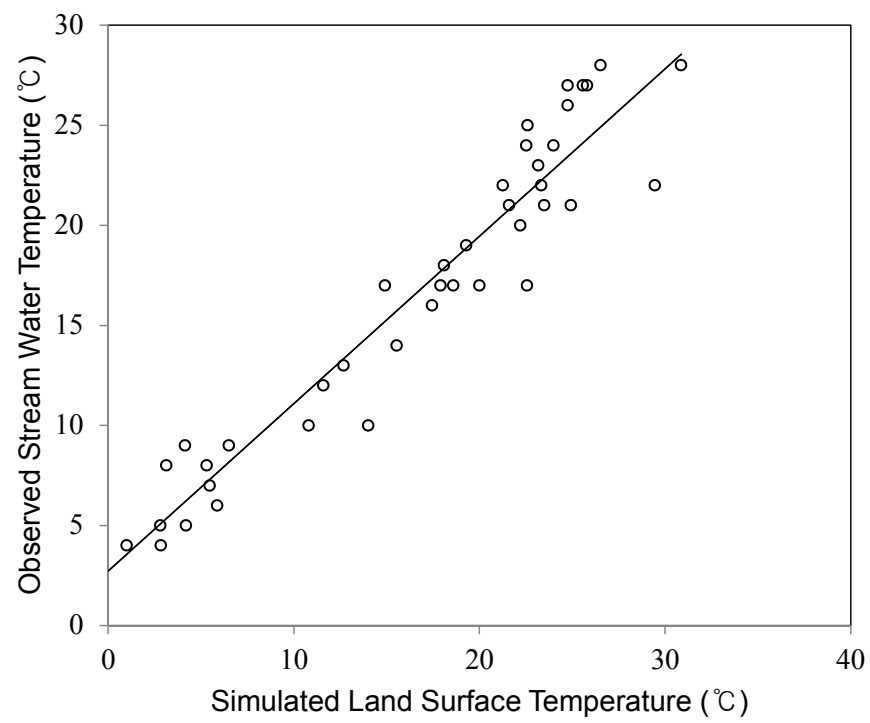

Figure 9 depicts that daily stream water temperatures estimated Equation (14) track closely through the seasonal trend of 42 observations at the KMA stream gauge station Y-A in 2009. It is expected that the regression equation can be used to estimate the stream water temperature variations and the daily water temperature at a local stream reach can be continuously predicted by the land surface temperature result from the CoLM under more evaluations with long-term data for this study basin.

Figure 9. Comparison of daily time series of stream water temperatures estimated from the regression analysis with the $1-\mathrm{km}$ CoLM land surface temperature simulation results along with 42 stream water temperature observations at the KMA stream gauge station Y-A in 2009.

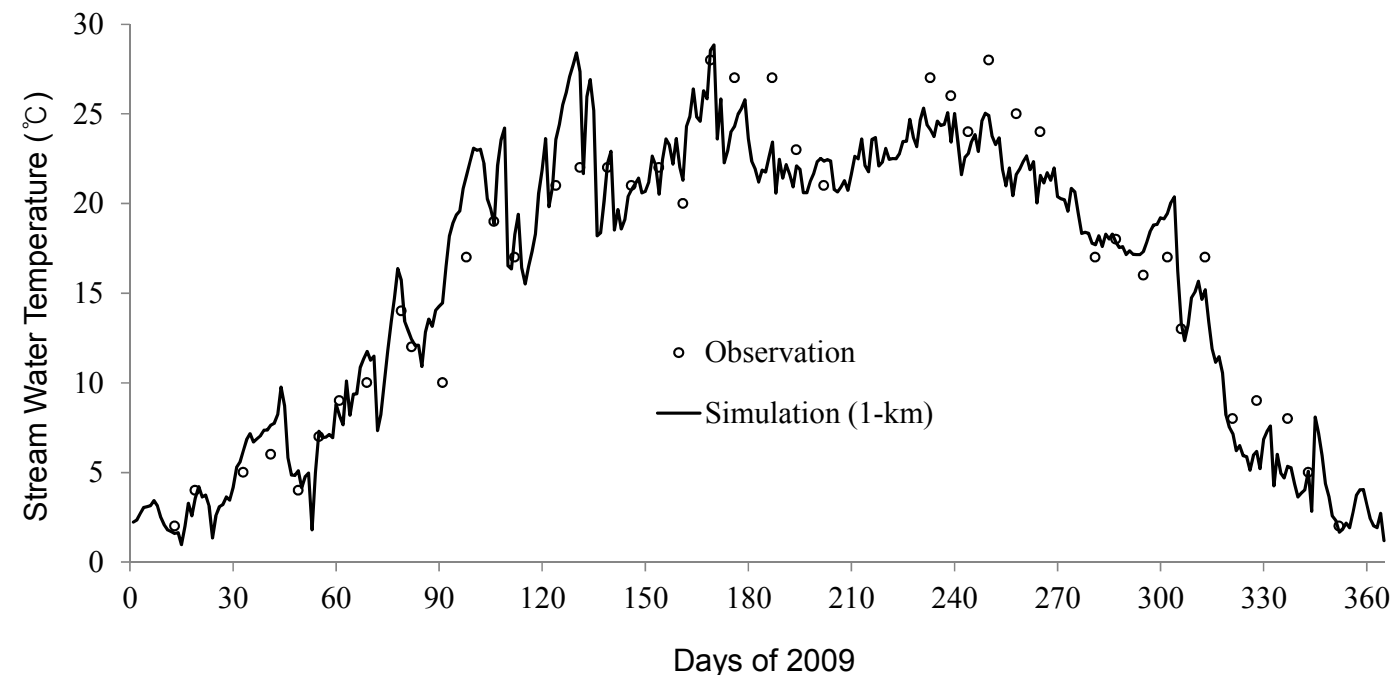




\section{Conclusions}

This study has assessed the performance of the Common Land Model (CoLM) in a set of offline simulations of daily runoff and land surface temperatures for a small natural basin, the Yongjeon River Basin under study in the Nakdong River Watershed of Korea for its applicability to high resolution simulations. The high-resolution simulations from the CoLM were feasible with the high resolution surface boundary conditions (SBCs) from remote sensing data and meteorological forcings constructed for the study basin at $1-\mathrm{km}$ horizontal spacing. This study has constructed high quality SBCs and meteorological forcing data at both $1-\mathrm{km}$ and $30-\mathrm{km}$ resolutions to drive the CoLM model in the offline mode. The comparison of the CoLM simulation results indicates that performance of a finer $(1-\mathrm{km})$ resolution result is much better than a coarser $(30-\mathrm{km})$ resolution result in both runoff and land surface temperature predictions. The $1-\mathrm{km}$ high-resolution simulation results for runoff and temperatures from the CoLM showed generally favorable correspondence with the stream gauge historical data and the Moderate Resolution Imaging Spectroradiometer (MODIS) observations in 2009. It is observed that the daily runoff simulated from the CoLM at the $1-\mathrm{km}$ scale can capture the temporal variations in stream flow discharge observations for the study basin, although the limited 42 observations in 2009 are not sufficient to fully evaluate the model runoff predictability especially for the high flow season. The land surface temperature result from the CoLM at the $1-\mathrm{km}$ scale can simulate well the seasonal trend of 8-day observations from the 1-km MODIS product for the study domain. These results indicate that the CoLM incorporating high quality SBCs based on remote sensing products can reasonably estimate the water and energy fluxes at a 1-km resolution. This study has also demonstrated that the stream water temperature can be estimated by the 1-km land surface temperature simulation result through a linear regression equation, which needs to be fully evaluated for further simulation results. A robust technique for the stream water temperature prediction at a local stream scale is required to develop comprehensive maps of water temperature distribution for stream networks throughout the year, which can provide the significant information on water quality and ecosystem managements for river water resources.

In the context of such issues and challenges for the small watershed forecasting, management, and planning, this study has initially implemented high-resolution simulations for runoff and land surface temperatures from the CoLM at the $1-\mathrm{km}$ grid for a small spatial and temporal scale in the offline mode. It is expected that high-resolution simulations from the current LSMs can improve model predictability for better predictions of the surface water and energy balance crucial to climate variability and change studies. Future studies will be required to construct more consistent and realistic SBCs and meteorological data from more remote sensing products at finer resolutions for long-term periods, and an upcoming paper will address the RCM climate analysis sensitivity to various scales. In addition, based on the high-resolution implementations of land surface models (LSMs), an advanced

explicit scheme for the stream temperature computation needs to be incorporated into LSMs for the better prediction and decision-making in stream environmental managements against climate change. 


\section{Acknowledgments}

This work was supported by the National Research Foundation of Korea (NRF) grant funded by the Korea government (MEST) (NRF-2013R1A2A2A01008881), and the Yeungnam University Research Grant in 2013 (213A061013).

\section{Conflicts of Interest}

The author declares no conflict of interest.

\section{References}

1. Bates, B.C.; Kundzewicz, Z.W.; Wu, S.; Palutikof, J.P. Climate Change and Water; Technical Paper of Intergovernmental Panel on Climate Change; IPCC Secretariat: Geneva, Switzerland, 2008; p. 210.

2. Stieglitz, M.; Rind, D.; Famiglietti, J.; Rosenzweig, C. An efficient approach to modeling the topographic control of surface hydrology for regional modeling. J. Clim. 1997, 10, 118-137.

3. Chen, J.; Kumar, P. Topographic influence of the seasonal and interannual variation of water and energy balance of basins in North America. J. Clim. 2001, 14, 1989-2014.

4. Warrach, K.; Stieglitz, M.; Mengelkamp, H.-T.; Raschke, E. Advantages of a topographically controlled runoff simulation in a soil-vegetation-atmosphere transfer model. J. Hydrometeorol. 2002, 3, 131-148.

5. Niu, G.-Y.; Yang, Z.-L. The versatile integrator of surface and atmosphere processes (VISA) Part II: Evaluation of three topography based runoff schemes. Global Planet. Change 2003, 38, 191-208.

6. Niu, G.-Y.; Yang, Z.-L.; Dickinson, R.E.; Gulden, L.E. A simple TOPMODEL-based runoff parameterization (SIMTOP) for use in GCMs. J. Geophys. Res. 2005, 110, D21106.

7. Oleson, K.W.; Niu, G.-Y.; Yang, Z.-L.; Lawrence, D.M.; Thornton, P.E.; Lawrence, P.J.; Stockli, R.; Dickinson, R.E.; Bonan, G.B.; Levis, S.; et al. Improvements to the community land model and their impact on the hydrological cycle. J. Geophys. Res. 2008, 113, G01021.

8. Choi, H.I.; Liang, X.-Z. Improved terrestrial hydrologic representation in mesoscale land surface models. J. Hydrometeorol. 2010, 11, 797-809.

9. Dai, Y.; Zeng, X.; Dickinson, R.E.; Baker, I.; Bonan, G.B.; Bosilovich, M.G.; Denning, A.S.; Dirmeyer, P.A.; Houser, P.R.; Niu, G.; et al. The common land model. Bull. Am. Meteorol. Soc. 2003, 84, 1013-1023.

10. Liang, X.-Z.; Li, L.; Dai, A.; Kunkel, K.E. Regional climate model simulation of summer precipitation diurnal cycle over the United States. Geophys. Res. Lett. 2004, 31, L24208.

11. Liang, X.-Z.; Xu, M.; Zhu, J.; Kunkel, K.E.; Wang, J.X.L. Development of the Regional Climate-Weather Research and Forecasting Model (CWRF): Treatment of Topography. In Proceedings of the 2005 WRF/MM5 User's Workshop, Boulder, CO, USA, 27-30 June 2005; p. 5.

12. Liang, X.-Z.; Xu, M.; Yuan, X.; Ling, T.; Choi, H.I.; Zhang, F.; Chen, L.; Liu, S.; Su, S.; Qiao, F.; et al. Regional climate-weather research and forecasting model. Bull. Am. Meteorol. Soc. 2012, $93,1363-1380$. 
13. Niu, G.-Y.; Yang, Z.-L. Effects of frozen soil on snowmelt runoff and soil water storage at a continental scale. J. Hydrometeorol. 2006, 7, 937-952.

14. Qian, T.; Dai, A.; Trenberth, K.E.; Oleson, K.W. Simulation of global land surface conditions from 1948 to 2004: Part I: Forcing data and evaluations. J. Hydrometeorol. 2006, 7, 953-975.

15. Choi, H.I.; Kumar, P.; Liang, X.-Z. Three-dimensional volume-averaged soil moisture transport model with a scalable parameterization of subgrid topographic variability. Water Resour. Res. 2007, 43, W04414.

16. Niu, G.-Y.; Yang, Z.-L.; Dickinson, R.E.; Gulden, L.E.; Su, H. Development of a simple groundwater model for use in climate models and evaluation with gravity recovery and climate experiment data. J. Geophys. Res. 2007, 112, D07103.

17. Lawrence, P.J.; Chase, T.N. Representing a new MODIS consistent land surface in the Community Land Model (CLM3.0). J. Geophys. Res. 2007, 112, G01023.

18. Lawrence, D.M.; Thornton, P.E.; Oleson, K.W.; Bonan, G.B. The partitioning of evapotranspiration into transpiration, soil evaporation, and canopy evaporation in a GCM: Impacts on land-atmosphere interaction. J. Hydrometeorol. 2007, 8, 862-880.

19. Kim, E.S.; Choi, H.I.; Kim, S. Implementation of a topographically controlled runoff scheme for land surface parameterizations in regional climate models. KSCE J. Civil Eng. 2011, 15, 1309-1318.

20. Liang, X.-Z.; Choi, H.L.; Kunkel, K.E.; Dai, Y.; Joseph, E.; Wang, J.X.L.; Kumar, P. Surface boundary conditions for mesoscale regional climate models. Earth Interact. 2005, 9, 1-28.

21. Liang, X.-Z.; Xu, M.; Gao, W.; Kunkel, K.E.; Slusser, J.; Dai, Y.; Min, Q.; Houser, P.R.; Rodell, M.; Schaaf, C.B.; et al. Development of land surface albedo parameterization bases on Moderate Resolution Imaging Spectroradiometer (MODIS) data. J. Geophys. Res. 2005, 110, D11107.

22. Gao, W.; Gao, Z.Q.; Choi, H.I.; Xu, M.; Slusser, J.R. Construction of surface boundary conditions for regional climate modeling in China by using the remote sensing data. Proc. SPIE 2005, 5884, 331-335.

23. Choi, H.I. Use of sensor imagery data for surface boundary conditions in regional climate modeling. Sensors 2011, 11, 6728-6742.

24. Choi, H.I. Parameterization of high resolution vegetation characteristics using remote sensing products for the Nakdong River Watershed, Korea. Remote Sens. 2013, 5, 473-490.

25. Beven, K.J.; Kirkby, M.J. A physically based, variable contributing area model of basin hydrology. Hydrol. Sci. Bull. 1979, 24, 43-69.

26. Beven, K.J. On subsurface stormflow: An analysis of response times. Hydrol. Sci. J. 1982, 27, 505-521.

27. Beven, K.J. Infiltration into a class of vertically non-uniform soils. Hydrol. Sci. J. 1984, 29, 425-434.

28. Elsenbeer, H; Cassel, D.K.; Castro, J. Spatial analysis of soil hydraulic conductivity in a tropical rainforest catchment. Water Resour. Res. 1992, 28, 3201-3214.

29. Beven, K.J. Macropores and water flow in soils. Water Resour. Res. 1982, 18, 1311-1325.

30. Brooks, R.H.; Corey, A.T. Hydraulic Properties in Porous Media; Hydrology Paper No. 3; Colorado State University: Fort Collins, CO, USA, 1964; p.27. 
31. STRM 90m DEM Database V4.1. Consortium for Spatial Information (CSI), Consultative Group on International Agricultural Research (CGIAR): Washington, DC, USA, 2008. Available online: http://www.cgiar-csi.org/data/srtm-90m-digital-elevation-database-v4-1 (accessed on 30 September 2013).

32. FAO-IIASA. Harmonized World Soil Database (version 1.2); FAO: Rome, Italy/IIASA: Laxenburg, Austria, 2012.

33. GLCC Database. US Department of the Interior, US Geological Survey: Washington, DC, USA. Available online: http://edc2.usgs.gov/glcc/glcc.php (accessed on 30 September 2013).

34. AVHRR NDVI Database. US Department of the Interior, US Geological Survey: Washington, DC, USA. Available online: http://phenology.cr.usgs.gov/ndvi_avhrr.php (accessed on 30 September 2013).

35. Zeng, X.; Dickinson, R.E.; Walker, A.; Shaikh, M.; DeFries, R.S.; Qi, J. Derivation and evaluation of global $1-\mathrm{km}$ fractional vegetation cover data for land modeling. J. Appl. Meteorol. 2000, 39, 826-839.

36. Zeng, X.; Shaikh, M.; Dai, Y.; Dickinson, R.E.; Myneni, R. Coupling of the common land model to the NCAR community climate model. J. Clim. 2002, 15, 1832-1854.

37. Free VEGETATION Products. VITO: Belgium. Available online: http://free.vgt.vito.be (accessed on 30 September 2013).

38. MOD 15 LAI Data. US Geological Survey: Reston, VA, USA. Available online: https://lpdaac.usgs.gov/get_data (accessed on 30 September 2013).

39. Yucel, I. Effects of implementing MODIS land cover and albedo in MM5 at two contrasting US regions. J. Hydrometeorol. 2006, 7, 1043-1060.

40. Nash, J.E.; Sutcliffe, J.V. River flow forecasting through conceptual models part I-A discussion of principles. J. Hydrol. 1970, 10, 282-290.

41. Choi, H.I.; Liang, X.-Z.; Kumar, P. A conjunctive surface-Subsurface flow representation for mesoscale land surface models. J. Hydrometeorol. 2013, 14, 1421-1442.

(C) 2013 by the authors; licensee MDPI, Basel, Switzerland. This article is an open access article distributed under the terms and conditions of the Creative Commons Attribution license (http://creativecommons.org/licenses/by/3.0/). 